\title{
What makes a person a physicist? Learning Assistant and physics major views
}

\author{
Jason T. Starita and Gary D. White \\ Department of Physics, George Washington University, 725 21st St. NW, Washington DC, 20052 \\ Tiffany-Rose Sikorski \\ Graduate School of Education and Human Development, \\ George Washington University, 2136 G St. NW, Washington DC, 20052
}

\begin{abstract}
Using the theoretical framework of community of practice and physics identity, we investigate student perceptions of the physics community and competency among undergraduates at George Washington University, a mid-sized private research university. We analyze fifteen interviews of students belonging to three different populations: physics majors who are not Learning Assistants (LAs), physics majors who are LAs, and LAs who are not physics majors. By analyzing themes in participants' interview responses, we hope to better understand student perceptions of community. In general, physics majors report that they do not perceive themselves as physicists because they do not yet have, in their view, the competencies of professional physicists, yet the rigidity with which they hold onto this perspective is somewhat setting dependent.
\end{abstract}

2020 PERC Proceedings edited by Wolf, Bennett, and Frank; Peer-reviewed, doi.org/10.1119/perc.2020.pr.Starita Published by the American Association of Physics Teachers under a Creative Commons Attribution 4.0 license. Further distribution must maintain the cover page and attribution to the article's authors. 


\section{INTRODUCTION}

Students differ in their perceptions of what it means to be a physicist [1]. As students have different physics-related experiences, their perceptions of what being a physicist entails may change. These changing perceptions may influence how students reflect on their own development as a physicist [2]. Irving and Sayre [3] found that there are several factors, including engaging in research, that may lead to students feeling like more central members in the community of practice $[4,5]$ of professional physicists. The intent of this study is to compare and contrast the perception of physicists among students who participate in two activities; major in physics and participation in the physics Learning Assistant (LA) program.

LAs are undergraduate students who help increase the quantity and quality of peer interaction in STEM courses [6]. They attend class and facilitate group discussions and problem solving, host office hours and review sessions, and meet with the instructor weekly to discuss patterns in student reasoning and engagement, and plan for class. LAs are recruited from a variety of majors (within and beyond STEM). At the site where this study was conducted, all physics LAs take a pedagogy course to reflect on their classroom experiences, practice LA techniques, and investigate broader pedagogical issues in STEM. Recent research [7, 8] has studied the development and transformation of LA physics identity through participation in an LA program. Close, Conn, and Close [8] have found that participation in the program may support a stronger physics identity that could potentially be due to an increased comfort in interactions with peers and faculty and the development of competency in physics.

This paper is part of a larger study wherein we investigated conceptions of community and belonging among the undergraduate participants in two groups at a mid-sized private research university, namely those identifying as physics majors and those in the LA program. We analyzed interviews of fifteen students with varying degrees of involvement in these two communities to learn how these activities may shape physics identity. In this paper we limit our focus to the student interview responses to prompts such as "Describe a typical physicist." and "Do you identify as a physicist?".

\section{BACKGROUND AND THEORETICAL FRAMEWORK}

This section gives an overview of relevant elements of the theoretical framework used in the analysis including the community of practice learning theory developed by Lave and Wenger [4,5] and the physics identity framework developed by Hazari and colleagues [9].

\section{A. Community of Practice}

Lave and Wenger [4, 5] developed a theory of learning concerned with the participation in communities of practice and how membership in a community may affect one's identity. The theory describes how individuals engage together in a shared practice and how an individual community member relates to others, and understands the meaning of interactions in the context of the community. Development of an identity as a member of an existing community of practice requires the possibility of moving from newcomer status in the community toward full membership. Identity is not a fixed quality but rather in constant flux depending on perceived membership status.

Irving and Sayre [2] have found upper-level physics undergraduates negotiate their membership in two communities of practice: the undergraduate physics students community and the community of professional physicists. Both communities have distinct, but intersecting, identities that may overlap due similar shared practices. A fully-developed undergraduate identity may not always result in membership in the community of physicists. However, the development of one's undergraduate identity is just one part of the trajectory of becoming a full-fledged member of the community of professional physicists [3].

\section{B. Physics Identity}

Hazari et al. [9] developed and validated a theoretical framework for physics identity using the data from over 10,000 college students generated from their responses to the Persistence Research in Science and Engineering (PRiSE) survey. Given to students in English classes, students characterized their interests and experiences in science. The physics identity construct was found to closely link to choice of a career in physics and willingness to persist in STEM fields. The developed physics identity framework composed of four dimensions: interest (one's desire to learn physics), performance (one's belief in their ability to perform physics tasks), competence (one's belief in their ability to understand physics content), and recognition (recognition from others as a physics person).

In later work, using a factor analysis of data from over 6,500 college students drawn from the Sustainability and Gender in Engineering (SaGE) survey, Lock, Hazari, and Potvin [10] found that student responses of performance and competence formed a single factor. Thus, the theoretical framework was simplified to only three dimensions: interest, performance or competence, and recognition. Our study of physics identity aligns with this updated framework.

\section{RESEARCH METHODS}

This section outlines the interview process used to collect data about student experiences. We report on what we learned from the interviewees' responses to specific questions about what makes a physicist, and whether these students identify as physicists. 


\section{A. Interviews}

Fifteen physics students participated in interviews about their experiences in physics: in classes, informal science programs, and in the LA program, if applicable. Participants reflect on experiences in science and articulate how these experiences affect how they perceive themselves. Of the fifteen students interviewed, ten interviewees have participated in the LA program, five of whom were also physics majors. Students who were LAs self-identified and six were women, four were Asian, one was Hispanic, and the remaining five were White. The other five interviewees were physics majors who have not participated in the LA program and self-identified that three were women, two were Hispanic and the others were White. All interviews were conducted by the first author and student investigator. As a senior undergraduate student in the department, the student researcher had preexisting relationships with many of the student interviewees. The student researcher's peer status may have influenced how comfortable students felt in the interview, what they were willing to share, and how they articulated their ideas.

The structured interview protocol was adapted from Hyater-Adams et al. [11] and modified to include questions regarding the LA experience. The interview protocol includes questions probing self-perceptions to focus on identity such as "What skills have you gained from studying physics?" and questions probing community membership including "Do you feel like you belong in the field of physics?". However, in this paper, we largely limit our discussion to the interviewee responses describing their perceptions of, and identification with, physicists.

\section{ANALYSIS}

After each interview was conducted, the student researcher transcribed the interview. We are specifically interested to understand how students discuss and conceptualize aspects of community, belonging, and identity. Instances when students discussed their experiences in the physics community were tagged in each interview. The student researcher then catalogued key ideas discussed in each of these instances, and compared the ideas across the different student populations.

We examine the data from the physics students through the analytic lens of the community of practice framework described in Section II A and the physics identity framework described in Section II B. In this work, we will see how the students' perception of their own competency, and to a lesser extent their interest and recognition from others, is reflected in their interview responses about what makes a physicist.

\section{A. Non-LA Physics Majors}

Among the five non-LA physics majors interviewed, there is a commonly repeated idea that physics students are differ- ent from physicists because of the amount of limited knowledge or skills (competence) they have developed thus far. We provide some specific examples in what follows.

When asked if she identifies as a physicist, Susan, a senior in the department, says that I identify as a physicist in training. I don't feel like I'm a full physicist yet because there is so much that I don't know. She later elaborates Like, I consider physicists to be a group of peers and I would not consider myself a peer to my professors. I consider them to have a level of expertise and knowledge that I am working towards. Susan says that because of the limits in her own content knowledge, she is not a physicist. She acknowledges that the community of practice $[4,5]$ comprised of her professors is a community she is not yet a part of. She does not consider herself a peer to her professors because of the limits in her content knowledge and competency [10] with the subject matter and thus does not yet consider herself a physicist.

Mark, a senior, has a similar idea; that he is not a physicist yet due to the limitations in his own knowledge. When asked how a typical physicist, such as a professor, would view him (in terms of being a 'physics person'), he answers I think both of them [physicists and professors] would think of everyone in the physics department as either physicist or aspiring physicists and whether or not that we each in the department reflect that internally, like I don't think I'm a physicist, but if everyone else seems to think I am... Mark does not consider himself a physicist, but rather an aspiring physicist, which is a similar idea to Susan's "physicist in training". Mark discusses that his identity is not only an internal idea, but is also affected by how those around him may view his identity as well. He states that if someone thinks he is a physicist, that might affect his own identity in that certain context. Mark's conception of his identity is consistent with the physics identity framework $[9,10]$ because he states that his identity is not static, but rather dependent on outside recognition.

Emma, a junior, also expresses that the knowledge one gains is essential to becoming a physicist. When asked if she identifies as a physicist she says immediately answers No. I mean I identify with the draws and interests, but I don't think I have enough skills or accumulated everything I can have to say that I'm a physicist yet. When prompted to elaborate on steps she needs to take to obtain the status of physicist, she responds Very specifically, I want to improve a lot of my math and coding science skills, my critical thinking, analysis, more broadly, I think I just need more experience and time. It is her interests in physics $[9,10]$ that draw Emma to the subject in the first place. She acknowledges that she has the same values and interests as those within the physics community. However, Emma cannot yet identify as a physicist because she does not have the other skills and knowledge that she will need to be a physicist. Much like Susan, her competency in the subject is not yet fully developed.

Finally, Kayla, a junior, described the differences between professional physicists and undergraduates. When asked to describe a typical physicist she says I suppose that would be a person, a scientist, who does some sort of physics, whether 
that would be research or educating others about physics or some combination and I wouldn't limit it to just people who have already their various degrees but anyone who is currently involved in the pursuit of physics. So it could include like students, like grad students, stuff like that. Here, Kayla says that being a physicist is not only limited to professors or those who have a degree, but anyone "involved in the pursuit of physics". Kayla interprets the word physicist to include those who are not a professional physicist or professor; the first time this distinction has arisen among non-LA physics majors. This is consistent with previous work [3] which finds that some students feel that anyone can be a physicist as long as they have the interests and mindset of a physicist. However, even though Kayla holds this conception that anyone involved can be a physicist, when asked if she would identify as a physicist she says I mean, no because I don't think I know enough physics to be a physicist but I don't think that's like- like I think students in general could be physicists I just wouldn't call myself one, I don't think I know enough information. Even while stating that those pursuing physics can be a physicist, she does not hold this true to herself because of the limitations in her knowledge. The idea that one's competency is essential to being a physicist is consistent with the ideas of Susan and Emma. Kayla's notion that anyone involved in physics, specifically students, can be a physicist does not match her own identity. Her unwillingness to identify as physicist herself indicates how one views a certain identity as a whole may differ from an individual's personal willingness to identify within that certain community.

While Nick, a sophomore, did not make any comments about professional physicists and his undergraduate identity, he straightforwardly answers "yes" when asked if he identifies as a physicist. Nick also repeats that in order to be considered a full-fledged physicist, one needs a certain level of expertise, knowledge, or competency; a level that undergraduate students do not possess, but are rather working towards.

\section{B. LA Physics Majors}

The five LA physics majors in our interview sample reveal a more nuanced view of what makes a physicist. Rather than painting a relatively binary picture of physicists and not-yetphysicists, they seem to be describing a broader set of possibilities, as described below.

James, a junior, says I feel like for a physicist there are no requirements or know a certain amount to be a physicist. I think anyone can become a physicist and the first thing is willing to wonder about something and be willing to answer that question and then to do your own work, or research to figure out the answer. Contrary to what other physics majors have said, James conveys there is no level of knowledge one needs to be a physicist, but rather it is one's curiosity and the questions one asks about the world. James places an ownership in order to be a physicist; it is the dedication to doing "your own work" or research into the question that makes one a physicist. James states that doing research independently is a critical aspect of becoming a physicist; an idea consistent with the work done by Irving and Sayre [3].

Because James expresses that anyone can be a physicist, when asked to describe what the journey of becoming a physicist looks like, he says that You propose a question, but it's different for us as physics students because we study a lot of physics, but I think that studying physics helps us to ask those questions sometimes. Like the more you study the more questions you may have about other stuff. Even though earlier he states that anyone can be a physicist, James thinks that the more one studies physics, the better one becomes at asking the questions a typical physicist might try to answer. This idea is similar to previous responses which state that as one gains more knowledge of the subject matter, one's competency is increased, and is therefore closer to becoming a physicist. When asked how a typical physicist might view him, James responds that Generally I think they [physicists] would see me as a physics student, still learning but maybe a physics student that asks a lot, or not even just me, but any student around my age, that has the ability to ask the questions of a physicist but maybe doesn't have the know how to answer those questions yet. James' view does appear to align with the idea that there are two separate communities: undergraduate physics students and professional physicists [2]. He seems to suggest a gradual progression from the undergraduate community to the professional physicist community, rather than an either-or situation. As someone who is still learning physics, he is becoming more competent at asking questions that a typical physicist might ask, which may help him get him closer to the title of physicist, but does not yet have the means to answer these questions. He indicates that for that reason, he is not a physicist yet, but rather still just a physics student.

When asked if she identifies as a physicist, Heather, a junior, explains that its weird because I'm studying physics but I'm gonna have to say no just because I don't want-as a-I don't want my job to be studying physics and I think for me that's what a physicist is. Heather appears to think that to be considered a physicist, it is the career one chooses, rather than the subject matter one chooses to study. This is consistent with Hazari et al. [9] who found that potential career choices influence one's interest in physics and physics identity. Heather's interest in physics is limited and do not correspond to a potential career so she does not identify with, nor does she want to identify with, the professional physicist community. She later describes her level of experience and says I don't feel like I am there yet. I don't feel like I'm ever going to be smart enough to call myself a physicist. I don't think I'm ever going to put in hours researching physics-like pure physics. Similar to the non-LA physics majors Susan, Emma, and Kayla, Heather says that she does not have enough knowledge to be considered a physicist. Furthermore, Heather places an importance on research to being a physicist but, unlike James, does not emphasize independent 
research. She does not feel like she possesses the dedication to research necessary to become a physicist.

As a senior in the department, Diane's perception of if she is a physicist or not is setting dependent. When asked if she identifies as a physicist, she explains that when I'm with my friends who are bio or IA [International Affairs] or poly sci, I'm like 'oh I'm a physicist, physics is what I do, I know how they think'. But when I'm in a setting where people are actual physicists, like the PhDs and they have multiple degrees and are doing research, I'm studying physics, I'm not a physicist. When she is surrounded by physicists, Diane does not consider herself one because she is still studying the subject. However, when she is not around professional physicists, Diane identifies more as a physicist. This supports the idea that identity is setting dependent and constantly in flux depending on the specific group of people one surrounds oneself with $[4,5]$. In a community of professional physicists, she assumes an undergraduate student identity but while in other spaces, Diane takes on a stronger physics identity.

Vincent, a senior, and Phillip, a junior, both immediately identify as physicists and do not offer clarification as to what may separate them as undergraduates from the professional physics community. While some students may choose to identify as a physicist, there is a repeated idea that physics majors, whether in the LA program or not, perceive that in order to be considered a physicist, one needs a certain level of expertise or knowledge that undergraduate students do not possess. Competency in physics is an essential component for developing a physics identity $[9,10]$. Participants in this study have indicated that this feeling is potentially influenced by the community one is in, the questions one may ask, or the career one may chose to pursue. Our non-LA physics majors seem to express more uniform views about physicists vs. notyet-physicists, while the LA physics majors views seem more varied.

\section{Non-Physics Major LAs}

While five non-physics major LAs were interviewed, Alice, a sophomore, was the only one to mention the community of undergraduates and professional physicists. All other non-physics major LAs discussed how they do not identify as physicists because they are studying something different, which could be further indication that education, experience, and competency are important aspects in becoming a physicist.

Alice expresses that there are differences between physicists and people who study physics. When asked if she would identify as a physicist, she responds I'd say I'm a person who's studied aspects of physics but I don't think I'm a physicist. She further explains and says Because my physics education-I did it in high school I did it one year in college. I wouldn't say my knowledge of physics is good enough to understand all aspects of physics. I don't have a deep enough education in physics to call myself a physicist. Just like Susan, Emma, Kayla, and Heather, Alice feels that she needs a certain level of competency before she can identify as a physicist. Alice's limited interactions with physics through high school and one year of college do not correlate with her own identity, but rather just "aspects" of the subject matter that have not lead to a competency level of a typical physicist.

\section{CONCLUSIONS AND INDICATIONS}

We saw much evidence of the physics identity framework $[9,10]$ and its three dimensions, interest, performance/competency, and recognition in our interviewees' comments about what makes a physicist. Our subjects talked more about the performance/competency dimension than about interest or recognition. Lave and Wenger [4, 5] state that membership in a community provides structure to a person's identity because of the competency one must develop to act in accordance within that community. As students share their perspectives with others in their community of practice, this may influence their competency within the context of the community [7]. Based on these interviews, there seems to be a critical component of student involvement in the physics community that one must recognize and accept their own limitations before becoming a central member of the community of practicing physicists. In this study, physics majors articulated many more factors that determine whether one is a physicist, compared to non-majors who primarily discussed choice of major. Irving and Sayre [2, 3] find that some students think that physicists are those who commit themselves to the study and pursuit of physics. Students who have not made the commitment to studying physics did not distinguish differences between undergraduate students and professional physicists. By not making a distinction, this may indicate that one is either majoring in physics and therefore is a physicist (or "aspiring physicist"), or one majors in something else and therefore is not a physicist.

Previous research on LA identity development $[7,8]$ suggests that experiences in the LA program support participants' physics identity development through the relationships with faculty and students they help in class. While these factors seem to indicate positive feelings of community, this study indicates that students involved in the program do not necessarily conceptualize their own involvement in the physics community if they are not majoring in physics. 
[1] P. W. Irving and E. C. Sayre, Physics identity development: A snapshot of the stages of development of upper-level physics students, J. Scholar. Teach. Learn. 13, 68 (2013).

[2] P. W. Irving and E. C. Sayre, Upper-level physics students' perceptions of physicists, in Proceedings of the International Conference of the Learning Sciences, 2014 (International Society of the Learning Sciences, Boulder, 2014), pp. 1513-1514.

[3] P. W. Irving and E. C. Sayre, Becoming a physicist: The roles of research, mindsets, and milestones in upper-division student perceptions, Phys. Rev. ST Phys. Educ. Res. 11, 020120 (2015).

[4] J. Lave and E. Wenger, Situated Learning: Legitimate Peripheral Participation (Cambridge University Press, Cambridge, England, 1991).

[5] E. Wenger, Communities of Practice: Learning, Meaning, and Identity (Cambridge University Press, Cambridge, England, 1998).

[6] A. Pak, M. Mangini, C. Green, and T. Sikorski, Talk moves, argumentation, and questioning patterns in LA-supported group problem solving, presented at the Physics Education Research
Conference 2018, Washington, DC, 2018.

[7] E. Close, J. Conn, and H. Close, Learning Assistants' Development of Physics (Teacher) Identity, presented at the Physics Education Research Conference 2013, Portland, OR, 2013.

[8] E. W. Close, J. Conn, and H. G. Close, Becoming physics people: Development of integrated physics identity through the Learning Assistant experience, Phys. Rev. Phys. Educ. Res. 12, 010109 (2016).

[9] Z. Hazari, G. Sonnert, P. Sadler, and M. C. Shanahan, Connecting high school physics experiences, outcome expectations, physics identity, and physics career choice: A gender study, J. Res. Sci. Teach. 47, 978 (2010).

[10] R. Lock, Z. Hazari, and G. Potvin, Physics Career Intentions: The Effect of Physics Identity, Math Identity, and Gender, presented at the Physics Education Research Conference 2012, Philadelphia, PA, 2012.

[11] S. Hyater-Adams, C. Fracchiolla, N. Finkelstein, and K. Hinko, Critical look at physics identity: An operationalized framework for examining race and physics identity, Phys. Rev. Phys. Educ. Res. 14, 010132 (2018). 